\title{
Modulation of RhoGTPases Improves the Behavioral Phenotype and Reverses Astrocytic Deficits in a Mouse Model of Rett Syndrome
}

\author{
Bianca De Filippis', Alessia Fabbri', Daiana Simone', Rossella Canese', Laura Ricceri', \\ Fiorella Malchiodi-Albedi ', Giovanni Laviola*, ${ }^{*, 3}$ and Carla Fiorentini ${ }^{2,3}$ \\ 'Department Cell Biology and Neuroscience, Istituto Superiore di Sanità, Roma, Italy; ${ }^{2}$ Department Therapeutic Research and Medicines \\ Evaluation, Istituto Superiore di Sanità, Roma, Italy
}

\begin{abstract}
RhoGTPases are crucial molecules in neuronal plasticity and cognition, as confirmed by their role in non-syndromic mental retardation. Activation of brain RhoGTPases by the bacterial cytotoxic necrotizing factor I (CNFI) reshapes the actin cytoskeleton and enhances neurotransmission and synaptic plasticity in mouse brains. We evaluated the effects of a single CNFI intracerebroventricular inoculation in a mouse model of Rett syndrome (RTT), a rare neurodevelopmental disorder and a genetic cause of mental retardation, for which no effective therapy is available. Fully symptomatic MeCP2-308 male mice were evaluated in a battery of tests specifically tailored to detect RTT-related impairments. At the end of behavioral testing, brain sections were immunohistochemically characterized. Magnetic resonance imaging and spectroscopy (MRS) were also applied to assess morphological and metabolic brain changes. The CNFI administration markedly improved the behavioral phenotype of MeCP2-308 mice. CNFI also dramatically reversed the evident signs of atrophy in astrocytes of mutant mice and restored wt-like levels of this cell population. A partial rescue of the overexpression of IL-6 cytokine was also observed in RTT brains. CNFI-induced brain metabolic changes detected by MRS analysis involved markers of glial integrity and bioenergetics, and point to improved mitochondria functionality in CNFI-treated mice. These results clearly indicate that modulation of brain RhoGTPases by CNFI may constitute a totally innovative therapeutic approach for RTT and, possibly, for other disorders associated with mental retardation.
\end{abstract}

Neuropsychopharmacology (2012) 37, I I52-I I63; doi:I0. I038/npp.20 I I.30 I; published online 7 December 20I I

Keywords: neurodevelopmental disorders; mental retardation; transgenic mice; neural plasticity; mitochondria; brain imaging

\section{INTRODUCTION}

Proteins belonging to the RhoGTPases' family, including Rho, Rac, and Cdc42 subfamilies, have a crucial role in neural plasticity and act as molecular switches (EtienneManneville and Hall, 2002) that respond to extracellular stimuli and induce dynamic changes in neuronal and glial morphology and functionality (Feltri et al, 2008; Hall, 2005; Luo, 2000; Nakayama et al, 2000; Tashiro et al, 2000). In line with their central role in controlling structural plasticity and actin cytoskeleton dynamics (Etienne-Manneville and Hall, 2002; Hall, 2005), aberrant Rho signaling has been reported to be associated with abnormalities in dendrites and spines in non-syndromic mental retardation, and to be responsible

*Correspondence: Dr G Laviola, Department Cell Biology and Neuroscience, Istituto Superiore di Sanità, Viale Regina Elena, 299, 00 I6I Roma, Italy, Tel: + 390649902 105, Fax: + 39064957821,

E-mail: giovanni.laviola@iss.it

${ }^{3}$ Equally senior authors.

Received 16 July 2011 ; revised 28 October 2011 ; accepted 28 October 2011 for cognitive impairments (Ramakers, 2002; van Galen and Ramakers, 2005).

In line with these observations, activation of brain RhoGTPases by intracerebroventricular (icv) inoculation of the cytotoxic necrotizing factor 1 (CNF1), an Escherichia coli toxin, which catalyzes the deamidation of a single glutamine residue of the RhoGTPases (Lemichez et al, 1997; Schmidt et al, 1997), enhances learning and memory performances, induces a re-arrangement of cerebral actin cytoskeleton and enhances neurotransmission and synaptic plasticity in mice. All these effects persist for weeks and are strictly dependent on RhoGTPases activation (De Viti et al, 2010; Diana et al, 2007; Pavone et al, 2009).

Recently, Rho GTPases signaling pathways have been suggested to be involved in the pathophysiology of a clinical variant of Rett syndrome (RTT) (Chen et al, 2011b), a rare and severe neurodevelopmental disorder and a genetic cause of mental retardation. About $90 \%$ of classic RTT cases are caused by mutations in the methyl-CpG-binding protein 2 (MeCP2) gene (Amir et al, 1999; Chahrour and Zoghbi, 2007). MeCP2 has multifunctional roles at the cellular level, mainly acting as a regulator of transcription (Chahrour 
et al, 2008; Hite et al, 2009; Ogier and Katz, 2008). Anatomical features in brains of RTT patients and MeCP2-null mice include reduced dendritic arborization and dendritic spine formation as well as reduced synaptic plasticity (Belichenko et al, 2009; Gonzales and LaSalle, 2010; Moretti et al, 2006). Recently, functional abnormalities in cultured astrocytes have been ascribed to MeCP2 deficiency, which may impact neuronal dendritic maturation (Ballas et al, 2009; Cahoy et al, 2008; Maezawa et al, 2009; Nagai et al, 2005). No cure currently exists for this disabling disorder.

Notably, among the extracellular stimuli affecting RhoGTPases activity, well-established $M e C P 2$ gene targets have been reported, such as brain-derived neurotrophic factor and corticotropin-releasing hormone (Chang et al, 2006; McGill et al, 2006; Miyamoto et al, 2006; Swinny and Valentino, 2006). The MeCP2-deficient state in RTT brains could therefore prevent RhoGTPases from properly carrying out their functions.

To assess whether pharmacological interventions targeting RhoGTPases may be an effective therapeutic strategy for RTT, we evaluated the effects of a single icv injection of CNF1 at an advanced stage of the disease on RTT-like symptomatology and pathophysiological features in MeCP2-308 hemizygous ( $\mathrm{hz}$ ) male mice, a model of RTT that expresses a truncated form of the $M e C P 2$ gene (De Filippis et al, 2010; Moretti et al, 2005, 2006; Shahbazian et al, 2002). Magnetic resonance imaging (MRI) and spectroscopy (MRS), powerful non-invasive techniques, also allowed detailed in vivo detection of morphological, functional and metabolic features of the disease in selected brain areas as well as the effects of CNF1 treatment thereon.

\section{MATERIALS AND METHODS}

\section{CNF1 Preparation}

CNF1 was obtained from the 392 ISS strain kindly provided by $\mathrm{V}$ Falbo (Rome, Italy) and purified as previously described (Falzano et al, 1993). In all experiments, the recombinant protein CNF1 C866S, in which the enzymatic activity on RhoGTPases is abrogated by change of cystein with serine at position 866 (Schmidt et al, 1998), was used as a control. The plasmid coding for CNF1 C866S, purified as previously described (Falzano et al, 1993), was kindly provided by E Lemichez (U627 INSERM, Nice, France). For further details, see Supplementary Methods.

\section{Animals}

To evaluate the efficacy of CNF1 on advanced RTT symptomatology, the experimental subjects were 8 months old hz male MeCP2-308 mice (B6.129S-MeCP2tm1Hzo/J, stock number: 005439; backcrossed to C57BL/6J mice for at least 12 generations from the Jackson Laboratories (USA)) and wt littermates. All procedures were carried out in accordance with the European Communities Council Directive (86/609/EEC) and formally approved by Italian Ministry of Health. For further details, see Supplementary Methods.

\section{Icv Injections of CNF1}

Mice were icv injected with $2 \mu \mathrm{l}$ of either the CNF1 solution $\left(10^{-10} \mathrm{M}\right)$ or the recombinant protein CNF1 C886S $\left(10^{-10} \mathrm{M}\right)$ (as in De Viti et al, 2010; Diana et al, 2007; Pavone et al, 2009) over $1 \mathrm{~min}$ at the following coordinates: $\mathrm{AP}=0.0 ; \mathrm{ML}=+0.72 \mathrm{DV}=-2.0$ relative to bregma to target lateral ventricles. For further details, see Supplementary Methods.

\section{Behavioral Testing}

A battery of behavioral tests was carried out to determine CNF1 effects on cognition and motor function, the most affected behavioral domains in RTT.

Contextual and cued fear-conditioning tests. To evaluate CNF1 effects on cognitive abilities, 2 weeks after icv injection, mice underwent a cued and contextual fearconditioning test as described in (Moretti et al, 2006). For further details, see Supplementary Methods.

Nest-building behavior. To evaluate forelimb motor capacities in a nest-material manipulation task, one piece of filter paper $(10 \times 12 \mathrm{~cm} ; 1 \mathrm{~g})$ was provided to each singly housed mouse three weeks after icv injection (see also, Moretti et al, 2005). After 1, 48 and $72 \mathrm{~h}$, quality of the nests was scored by a trained observer, blind to mouse genotype and treatment, using a four-point scale (Deacon, 2006).

Home-cage spontaneous activity and its circadian variation. Spontaneous locomotor activity in the homecages was monitored continuously for $24 \mathrm{~h}$ for 7 days, 4 weeks after the icv injection (De Filippis et al, 2010). The assessment of daily spontaneous activity was carried out by means of an automatic device using small passive infrared sensors positioned on the top of each cage (ACTIVISCOPE system, NEWBEHAVIOR, website: www.newbehavior.com). For further details, see Supplementary Methods.

\section{Immunofluorescence and Morphometric Analysis of Brain Sections}

After behavioral testing, an immunohistochemical analysis was conducted to characterize neuronal and astrocytic components in brain sections from MeCP2-308 mice and their wt littermates and CNF1 effects thereon. The neuronal cell populations were characterized in the hippocampus (dentate gyrus and CA1) and motor cortex. Immunoreactivity for GFAP, a specific marker of astrocytic cytoskeleton, was analyzed and morphometrically measured in brain areas that contain the two principal types of astrocytes, that is, hippocampus, which contains protoplasmic (grey matter type) astrocytes, and corpus callosum, which contains fibrous (white matter types) astrocytes. Morphometric analysis was performed as already described (Popoli et al, 2002). GFAP-positive area of each field, expressed as $\mu \mathrm{m}^{2}$ gave the astrocytic mean cell area for that field. Values obtained for each field were pooled to obtain a single mean value for each animal. In dentate gyrus, where single astrocytic cells could be more easily identified, the number of astrocytes was also counted in each field. In frozen 
sections from control mice, receiving the placement of the needle or the injection of $2 \mu \mathrm{l}$ of vehicle, differences in GFAP immunolabeling were also evaluated (see Supplementary Results and Supplementary Figure S3). For further details, see Supplementary Methods.

\section{GFAP Western Blot Analysis}

To confirm our immunohistochemical results, hippocampal GFAP content was determined by western blot. Twenty-five micrograms of total protein extracts were resolved on $10 \%$ SDS-PAGE and electrically transferred onto PVDF membranes. Following membranes blocking in TBS-T containing $5 \%$ skimmed milk, primary antibodies were added for $18 \mathrm{~h}$ at $4{ }^{\circ} \mathrm{C}$. After washing, immunocomplexes were detected with HRP-conjugated species-specific secondary antibodies followed by enhanced chemiluminescence reaction. For further details, see Supplementary Methods.

\section{Enzyme-Linked Immunosorbent Assay}

Cytokines have an important physiological role in synaptic plasticity, neurogenesis, and neuromodulation (McAfoose and Baune, 2009). As Rho GTPases are known to negatively control inflammatory cytokine expression in astrocytes, we evaluated whether the expression of IL-6, IL-1 $\beta$, and TNF- $\alpha$ is altered in MeCP2-308 mice and CNF1-induced activation of Rho GTPases can influence their expression in mouse brain tissue.

Brain levels of IL- 6 , IL- $1 \beta$, and TNF- $\alpha$ were analyzed by using microtiter wells plates coated with anti-mouse IL antibodies (BioVendor-Laboratorni, Czeck Republic) according to the manufacturer's instructions. The absorbance was read on a spectro-photometer (Bio-Rad) using $450 \mathrm{~nm}$ as the primary wave length, with a sub-wave length of $650 \mathrm{~nm}$.

\section{MRS and MRI Experiments}

Brain morphometric MRI analyses were carried out to determine whether the atrophic features of astrocytes were accompanied by a decreased brain volume in Mecp2-308 mice and CNF1 effects thereon. MRI evaluations were focused on brain areas that had been previously shown to be reduced in MeCP2-null mice: whole brain, motor cortex, and corpus callosum (Nag et al, 2009; Saywell et al, 2006). Given the well-recognized role of the striatum and the hippocampus in the control of motor function and cognition, respectively, metabolic features of the disease and the effects of CNF1 treatment were evaluated by quantitative MRS in these brain areas.

One month after CNF1 administration, animals were anaesthetized with $3.5 \%$ sevoflurane in oxygen $21 / \mathrm{min}$ (Sevoflo, Abbott SpA, Latina, Italy) within an induction chamber. All MRI and MRS experiments were conducted on a 4.7 T Varian Inova animal system (Varian, Palo Alto, CA), equipped with actively shielded gradient system (max $200 \mathrm{mT} / \mathrm{m}, 12 \mathrm{~cm}$ bore size). A $6-\mathrm{cm}$ diameter volume coil was used for transmission in combination with an electronically decoupled receive-only surface coil (Rapid Biomedical, Rimpar, Germany). A quantitative MRS protocol, including water T2 measurements, was applied (Canese et al, 2011). Spectra were analyzed using LCModel
(Provencher, 1993). Multislice fast spin echo axial images $(\mathrm{TR} / \mathrm{TE}$ eff $=3200 / 60 \mathrm{~ms}, \mathrm{~ns}=4$, slice thickness $0.6 \mathrm{~mm}, 24$ slices, matrix $256 \times 256$, FOV $=25 \times 25 \mathrm{~mm}^{2}$, which correspond to voxel resolution of $98 \times 98 \times 600 \mu^{3}$ ) were acquired for corpus callosum analyses. For further details, see Supplementary Methods online.

\section{Data Analysis}

Data are mean \pm SEM. Parametric analyses of variance (ANOVA) were performed on all data. Post hoc comparisons were performed using Tukey's test, which can be also used in the absence of significant ANOVA results (Wilcox, 1987). For further details, see Supplementary Methods.

\section{RESULTS}

\section{CNF1 Treatment Improves the Behavioral Phenotype of MeCP2-308 Mice}

Cnf1 treatment significantly improved the cognitive performance of mutant mice in a fear-conditioning task. No significant changes were found as for inactivity levels during baseline (Figure 1a). In addition, the performance in the cued test was not affected by either genotype or treatment (\% inactivity levels: wt control $=34.3 \pm 6.7$; wt $\mathrm{CNF} 1=33.0 \pm 5.8 ; \mathrm{hz}$ control $=39.9 \pm 9.7 ; \mathrm{hz} \mathrm{CNF} 1=$ $36.1 \pm 6.7)$.

Although inactivity levels were generally increased during the contextual test (in comparison with baseline values) (effect of phase: $\mathrm{F}(1,26)=54.57 ; p<0.001$ ), mutant mice showed a poorer performance in this cognitive task: unlike all the other experimental groups $(p<0.05)$, mutant control mice did not significantly increase their conditioned behavioral response during the test phase compared with baseline values (post hoc comparisons on the genotype $\star$ treatment $*$ phase interaction: $\mathrm{F}(1,26)=2.82 ; p=0.105)$ (Figure 1a). These results are in line with a previous report on the same RTT mouse model (Moretti et al, 2006).

CNF1 significantly increased the conditioned response during the contextual fear-conditioning task $(p<0.05$ after post hoc comparisons on the treatment $*$ phase interaction: $p=0.034)$. However, post hoc comparisons on the genotype $\star$ treatment $\star$ phase interaction $(\mathrm{F}(1,26)=2.82 ; p=0.105)$ revealed that only the performance of MeCP2-308 mice was significantly improved by CNF1 treatment $(p<0.05)$ (Figure 1a).

CNF1 improves mouth- and forelimb-dependent motor skills in mutant mice. As expected, when mice were followed for their ability to build a nest, the quality of the nests improved with time in all experimental groups (repeated measures: $\mathrm{F}(2,52)=40.64 ; p<0.001)$. However, in line with a previous report (Moretti et al, 2005), nestmaterial manipulation scores were generally lower in MeCP2-308 mice, suggesting a deficit in the integrated use of mouth and forelimbs $(p<0.05$ after post hoc comparison (wt control $v s \mathrm{hz}$ control at $72 \mathrm{~h}$ ) on the genotype $*$ repeatedmeasure interaction: $\mathrm{F}(2,52)=3.32 ; p=0.044$ ) (Figure $1 \mathrm{~b}$ ).

Importantly, the poor performance shown by MeCP2-308 mice was efficaciously improved by CNF1 treatment, which significantly increased the quality of the nests in both 
genotypes $(p<0.01$ after post hoc comparison (wt control $v s$ $\mathrm{hz}$ control at $72 \mathrm{~h}$ ) on the treatment $\star$ repeated-measure interaction: $\mathrm{F}(2,52)=3.67 ; p=0.032$ ) (Figure $1 \mathrm{~b}$ ).

Cnf1 restores wt-like levels of home-cage nocturnal activity in mutant mice. In line with previous reports in RTT mouse models (Moretti et al, 2005; Stearns et al, 2007), the evaluation of spontaneous locomotor activity during $24 \mathrm{~h}$ revealed that $\mathrm{MeCP} 2-308$ mice are generally less active than wt controls (genotype: $\mathrm{F}(1,24)=62.41 ; p=0.001$ ) and fail to exhibit the hyperactivity profile usually emerging
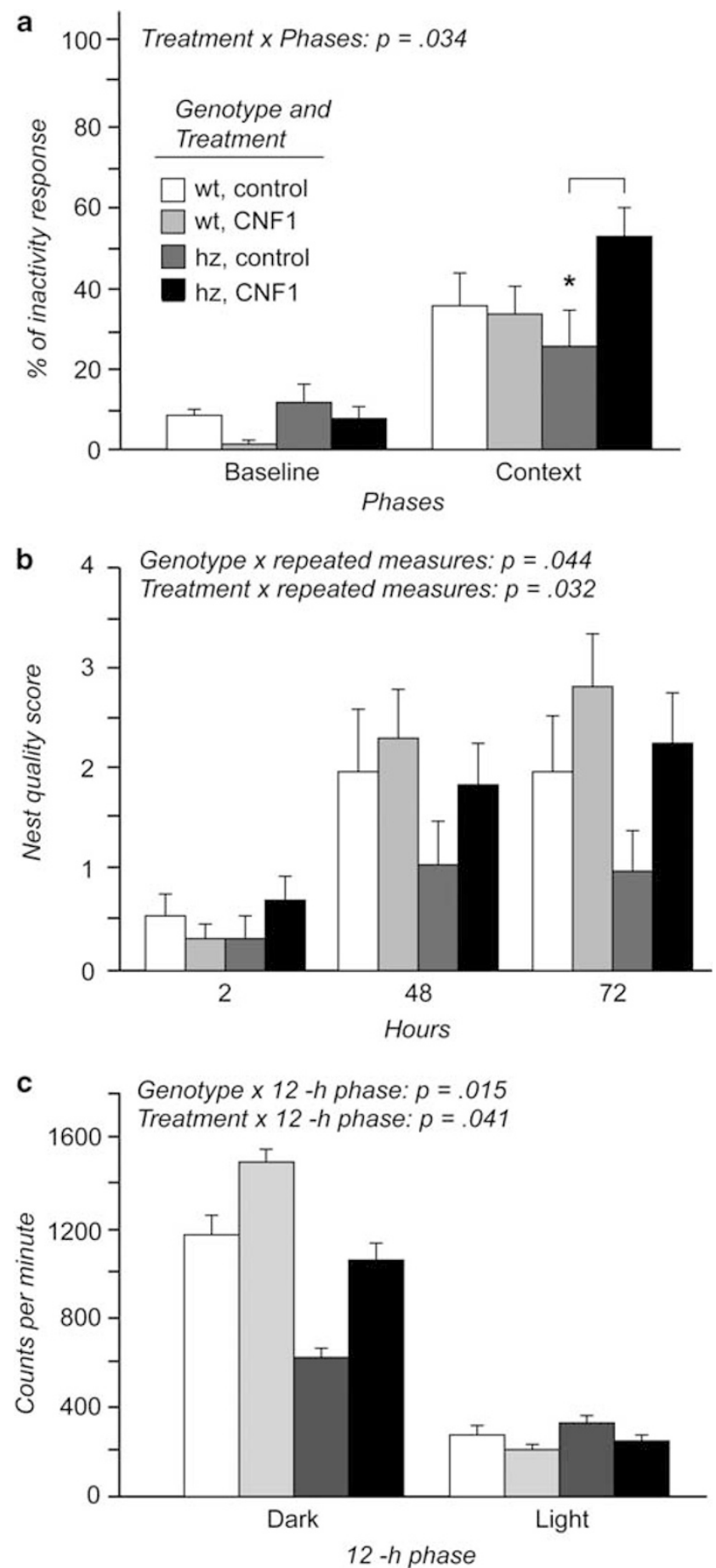

during the dark phase of the light/dark (L/D) cycle in rodents $(p<0.01$ after post hoc comparisons on the genotype $*$ phase interaction: $\mathrm{F}(1,24)=6.84 ; p=0.015)$ (Figure 1c).

Levels of activity exhibited during the dark phase of the L/D cycle appeared significantly increased in CNF1treated mice $(p<0.01$ after post hoc comparisons on the treatment $*$ phase interaction: $\mathrm{F}(1,24)=4.63 ; p=0.041)$. The nocturnal peak of locomotor activity in mutant mice was thus restored (Figure 1c).

\section{Astrocytes in MeCP2-308 Mice Show Atrophic Features, Which are Reversed by CNF1}

In line with a previous report (Moretti et al, 2006), no significant differences were observed between the genotypes in dendritic tree and synapses in hippocampus and motor cortex, and CNF1 did not have any effect on those markers (Supplementary Results and Supplementary Figure S2). Immunoreactivity of GFAP, a specific marker of astrocytic cytoskeleton, was analyzed in both dentate gyrus and corpus callosum, where astrocytes of grey and white matter types, respectively, are present. Both types of astrocytes in MeCP2-308 mice showed atrophic features, with fewer and poorly branched ramifications, when compared with wt animals. Morphometric analyses confirmed that GFAPpositive area was decreased in mutant mice. Although this difference was more marked in the dentate gyrus $(p<0.01$ after post hoc comparison on the genotype $x$ treatment interaction: $\mathrm{F}(1,16)=11.65 ; p=0.004$, Figure $2 \mathrm{a}$ and $\mathrm{c}$; Supplementary Figure S4a), a similar effect of genotype was also evident in the corpus callosum $(p<0.05$ after post hoc comparison on the genotypextreatment interaction: $\mathrm{F}(1,18)=3.66 ; p=0.072$, Figures $2 \mathrm{~b}$ and $\mathrm{d}$; Supplementary Figure S4b), thus suggesting that genotype effects are not limited to a single type of astrocytes. To better characterize the decrease in GFAP-positive area in mutant mice, astrocytic cell number (Figure $2 \mathrm{e}$ ) and astrocytic mean cell area (Figure 2f) were also calculated in dentate gyrus. The results showed a decrease in both parameters in mutant

Figure I CNFI treatment improved the behavioral phenotype in a mouse model of RTT. (a) The cognitive performance of MeCP2-308 mice in a contextual fear-conditioning task was significantly improved by CNFI treatment ( 12 days after CNFI administration). The effects of icv inoculation of CNFI C866S (control) or CNFI on learning and memory abilities were evaluated as the increase in conditioned inactivity from the baseline. ${ }^{*} p<0.05 ; N=7-9$. The recombinant protein CNFI C866S, in which the enzymatic activity on RhoGTPases is abrogated by change of cystein with serine at position 866, was used as a control. (b) CNFI icv inoculation improved nest material manipulation and nest construction abilities in fully symptomatic MeCP2-308 mice, thus rescuing the deficit in the integrated use of mouth and forelimbs (20 days after icv administration). The quality of the nest (score $=0-4$ ) was evaluated at 2,48 and $72 \mathrm{~h}$ after the introduction of nesting material into the cage. $N=7-9$. (c) CNFI restored wt-like levels of home-cage spontaneous circadian locomotor activity in fully symptomatic MeCP2-308 hemizygous (hz) mice, thus rescuing circadian cyclicity (I month after icv inoculation). The infrared sensors $(20 \mathrm{~Hz})$ detected any movement of mice with a frequency of 20 events per second. Scores were obtained as counts per minute (c.p.m.) expressed during I-h periods, and the 24-h profile of daily activity was obtained by averaging 7 days of continuous registration. $N=6-8$. 
a

GFAP - Dentate Gyrus

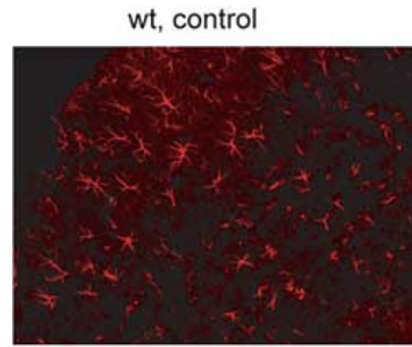

hz, control

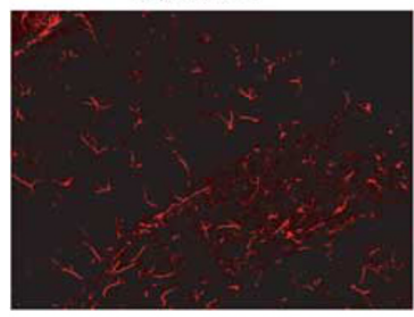

C

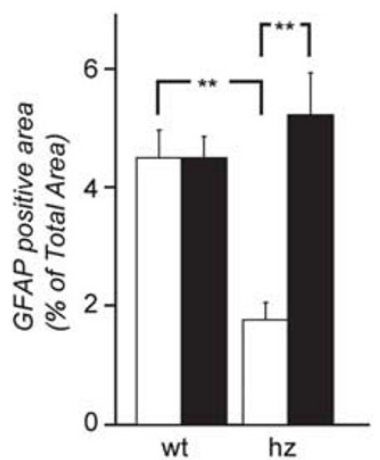

wt, CNF1

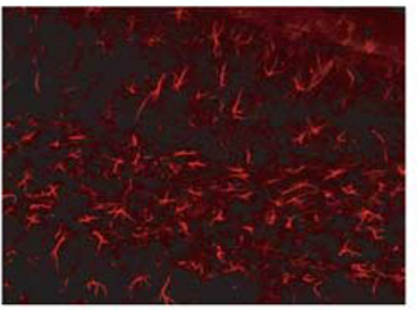

$\mathrm{hz}, \mathrm{CNF} 1$

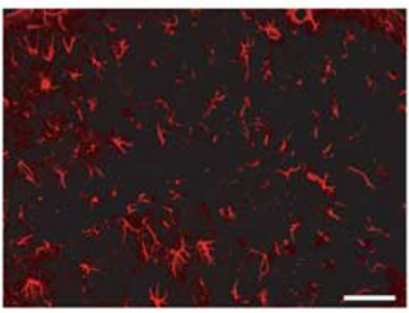

d

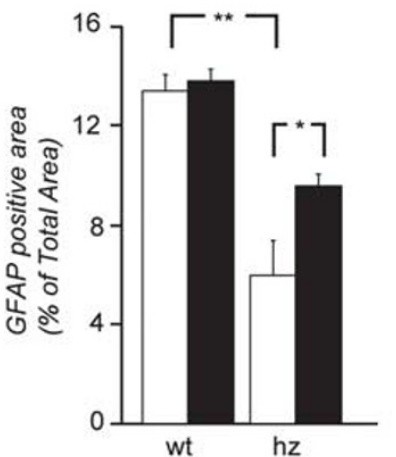

wt b

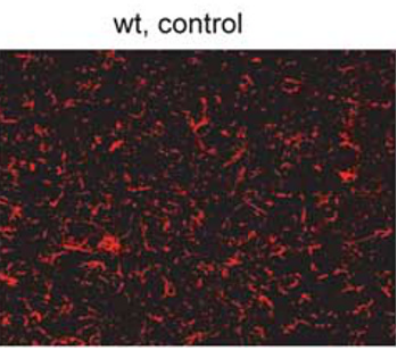

$\mathrm{hz}$, control

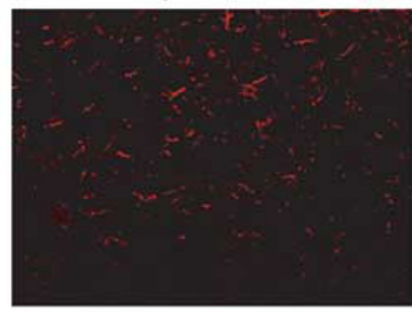

e

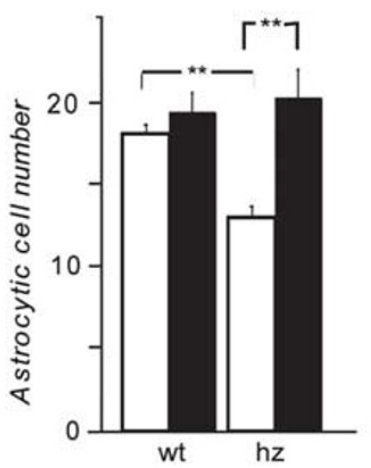

wt, CNF1

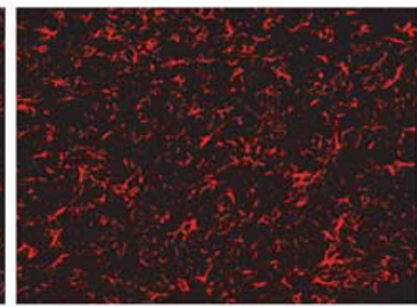

$\mathrm{hz}, \mathrm{CNF} 1$

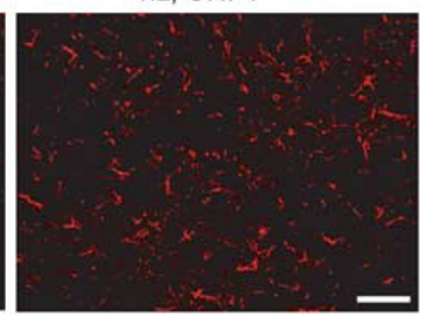

f Dentate Gyrus

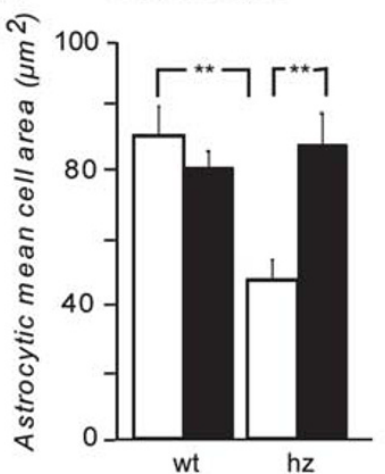

g

Hippocampus

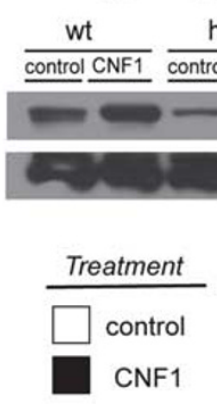

h

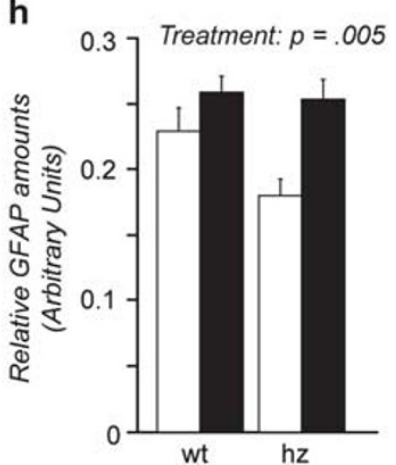

Figure 2 CNFI inoculation dramatically reversed astrocytic atrophy in a mouse model of RTT. The decrease in GFAP-immunoreactivity of astrocytes in MeCP2-308 hemizygous (hz) mice is counteracted by CNFI treatment in dentate gyrus (a) and corpus callosum (b). CNFI C866S was used as a control. $\mathrm{Bar}=50 \mu \mathrm{m}$. (c, d) Morphometric analysis of GFAP-positive area in dentate gyrus and corpus callosum, respectively: data are expressed as mean percentage of total area \pm SEM. $* p<0.05$, *** $p<0.01$. $N=5-4$. (e, f) Astrocytic cell number and astrocytic mean cell area in dentate gyrus. Data are expressed as mean \pm SEM. ${ }^{*} p<0.05, * * p<0.01$. N $=5-4$. (g, h) Western blot analysis confirmed an increase in GFAP content in the hippocampus after CNFI treatment.

brains $(p<0.05$ and $p<0.01$, respectively, after post hoc comparisons on the genotypextreatment interactions: cell number: $\mathrm{F}(1,16)=6.08 ; p=0.025$ and mean cell area: $\mathrm{F}(1,15)=10.79 ; p=0.005)$ and suggest that they equally contributed to determine a smaller GFAP-positive area in mutant mice.
Morphometric analysis of GFAP immunolabeling showed that CNF1 treatment increased GFAP-positive area in sections from both dentate gyrus and corpus callosum (treatment: $\mathrm{F}(1,16)=11.96 ; p=0.003$ and $\mathrm{F}(1,18)=5.30$; $p=0.033$, respectively, Figures $2 \mathrm{a}-\mathrm{d}$ ) and reversed the atrophic features of the two principal types of astrocytes in 
MeCP2-308 mice. In dentate gyrus, both astrocytic cell number (Figure 2e) and astrocytic mean cell area (Figure 2f) regained values close to $\mathrm{wt}$ after treatment with CNF1 $(p<0.01$ after post hoc comparisons on the genotype $x$ treatment interactions: cell number: $\mathrm{F}(1,16)=6.08 ; p=0.025$ and mean cell area: $\mathrm{F}(1,15)=10.79 ; p=0.005$, respectively).

In line with immunohistochemical results, western blot analysis on hippocampal tissue from MeCP2-308 mice and their wt littermates confirmed an increase in GFAP content after CNF1 treatment (treatment: $\mathrm{F}(1,8)=14.22 ; p=0.005$ ) (Figures $2 \mathrm{~g}$ and $\mathrm{h}$ ).

\section{CNF1 Significantly Contrasts IL-6 Overexpression in MeCP2-308 Brains}

IL-1 $\beta$ levels were unaltered in mutant mice and CNF1 did not have any effect on this cytokine (data not shown). TNF$\alpha$ was significantly decreased in MeCP2-308 mouse brains (genotype: $\mathrm{F}(1,13)=19.51 ; p<0.001$, Figure $3 \mathrm{a}$ ) and CNF1 did not modify it. By contrast, IL-6 expression was significantly increased in mutant brains when compared with wt mice (genotype: $\mathrm{F}(1,10)=107.88 ; \quad p<0.001$, Figure $3 \mathrm{~b})$. Icv inoculation of CNF1 selectively decreased IL-6 levels in MeCP2-308 mice, thus contrasting its overexpression ( $p<0.05$ after post hoc comparisons on the genotype $x$ treatment interaction: $\mathrm{F}(1,10)=10.34 ; p=0.009)$.

\section{CNF1-Induced Brain Morphological and Metabolic Changes in Mutant Mice}

Volumetric analyses. Microcephaly is a peculiar feature of RTT (Hagberg, 2002). Volumetric MRI analyses confirmed a reduction in the whole brain of MeCP2-308 mice (genotype: $\mathrm{F}(1,15)=10.81 ; p=0.005$ ) (Figure 4c). In

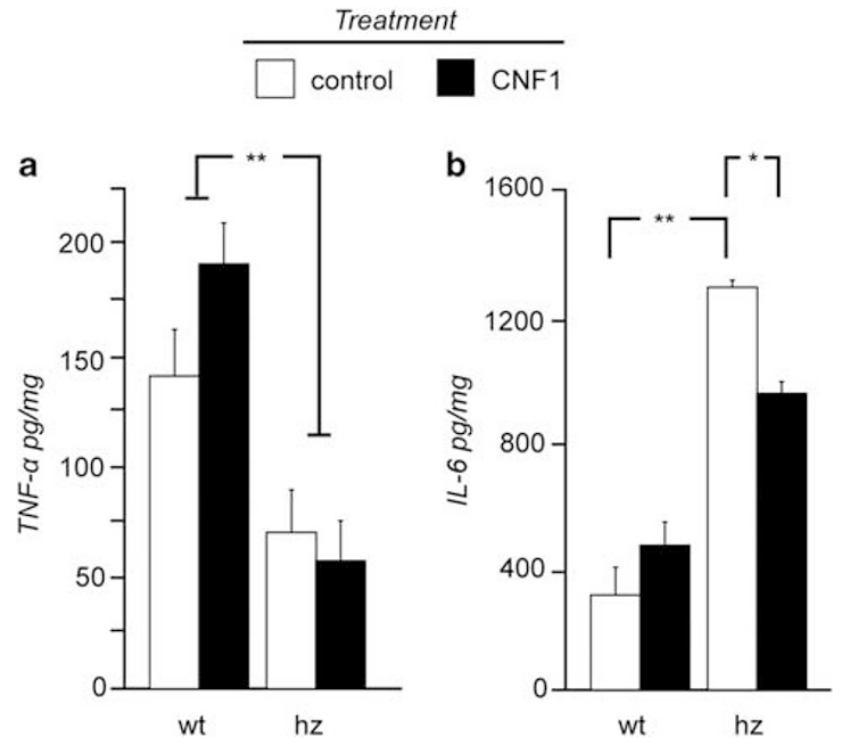

Figure 3 Cytokines expression abnormalities in brain tissues of mutant mice are partially rescued by CNFI treatment. CNFI C866S was used as a control. (a) In fully symptomatic MeCP2-308 hemizygous ( $\mathrm{hz}$ ) mouse brains, TNF- $\alpha$ expression was significantly decreased in comparison with wt mice. No treatment effects were evidenced. Data are mean \pm SEM. *** $<<0.01$. N=3-6. (b) CNFI icv inoculation significantly contrasted the overexpression of IL-6 in mutant mice. ${ }^{*} p<0.05$, ${ }^{*} * p<0.0$ I. $N=3-4$. agreement with recent imaging studies, which demonstrated a reduction in corpus callosum thickness, associated with white matter pathologic features in RTT patients (Gotoh et al, 2001; Mahmood et al, 2010), a significant reduction in both area (genotype: $\mathrm{F}(1,8)=9.11 ; p=0.017$ ) and thickness (genotype: $\mathrm{F}(1,8)=14.86 ; p=0.005)$ of the genu of the corpus callosum compared with wt values (Figures $4 \mathrm{a}$ and $\mathrm{b}$ ) was also found in MeCP2-308 mice. No changes were found in motor cortex of mutant mice and only a trend for increased motor cortex thickness was observed in CNF1treated mice $(\mathrm{F}(1,8)=4.69 ; p=0.062)$ (Figure $4 \mathrm{c}$ ).

Brain metabolic profiles. In vivo MRI-guided ${ }^{1} \mathrm{H}$ MRS analyses at $4.7 \mathrm{~T}$ detected differences in the spectra acquired in the striatum and the hippocampus of MeCP2-308, wt and treated mice. Water T2 analyses confirmed that no changes occurred in the T2s within the groups confirming that the alterations observed in the NMR signals correspond to changes in the levels of metabolites (Supplementary Table S1).

In the hippocampus, in line with immunohistochemical results, CNF1 significantly increased levels of the astrocytic marker myo-inositol (Ins) $(\mathrm{F}(1,13)=8.30 ; p=0.013)$, thus supporting our immunohistochemical results (Figures $4 \mathrm{~g}-\mathrm{i}$ ). Notably, in this brain area CNF1 treatment concomitantly increased metabolites involved in: bioenergetics (phosphocreatine $(\mathrm{PCr}): \mathrm{F}(1,9)=15.56 ; p=0.003$ and total creatine (Cr) (ie, $\mathrm{Cr}+\mathrm{PCr}$ ): $\mathrm{F}(1,13)=17.08 ; p=0.001$ ); synaptic efficiency (taurine (Tau): $\mathrm{F}(1,13)=24.23 ; p<0.001$ ); neuronal health (nacetylaspartate (NAA): $\mathrm{F}(1,13)=3.91 ; p=0.069$ and total NAA (ie, NAA + nacetylaspartylglutamate: $\mathrm{F}(1,13)=10.56 ; \quad p=0.006)) ; \quad$ phospholipid metabolism (phosphocoline (PCho) + glicerophosphocoline (GPC): $\mathrm{F}(1,13)=5.23 ; p<0.035)$ and the neurotrasmitter glutamate (Glu) $(\mathrm{F}(1,13)=5.22 ; p=0.026)$ (Figures $4 \mathrm{~g}-\mathrm{i})$. In the hippocampus, the NAA/total NAA ratio was increased in mutant mice $(p<0.05$ after post hoc comparison on the genotype treatment interaction: $\mathrm{F}(1,13)=4.96 ; p=0.044)$. CNF1 restored wt-levels in mutants, thus normalizing NAA metabolism $(p<0.05$ after post hoc comparison on the genotype $\star$ treatment interaction: $p=0.044$ ) (Supplementary Table S2). In line with a previous report (Saywell et al, 2006), mutant mice also showed increased choline-containing compounds (ie, PCho + GPC) $(\mathrm{F}(1,13)=5.56 ; p=0.040)$, suggesting abnormal phospholipid metabolism.

In line with our previous findings (Ricceri et al, 2011) suggesting a role for the striatum in the pathophysiology of RTT, CNF1-induced metabolic changes followed a different profile in this brain area: post hoc comparisons on the genotype $x$ treatment interactions revealed that wt-like levels of Ins $(\mathrm{F}(1,11)=6.21 ; p=0.030)$, Tau $(\mathrm{F}(1,12)=7.69$; $p=0.017)$, Glu $(\mathrm{F}(1,12)=5.02 ; p=0.047)$, total NAA $(\mathrm{F}(1,11)=7.01 ; p=0.023)$, and total $\mathrm{Cr}(\mathrm{F}(1,12)=12.60$; $p=0.004)$ were restored by CNF1 in mutant mice $(p<0.05)$, in the absence of changes in wt controls (Figures $4 \mathrm{e}-\mathrm{f}$ ).

\section{DISCUSSION}

At present, no cure exists for RTT patients. This study provides the first evidence of the potential efficacy of a new treatment based on modulation of RhoGTPases for RTT and 


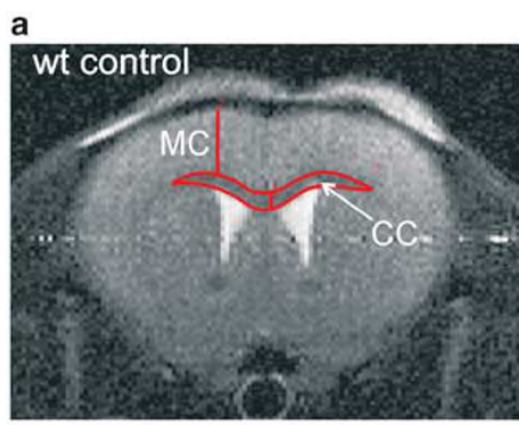

b

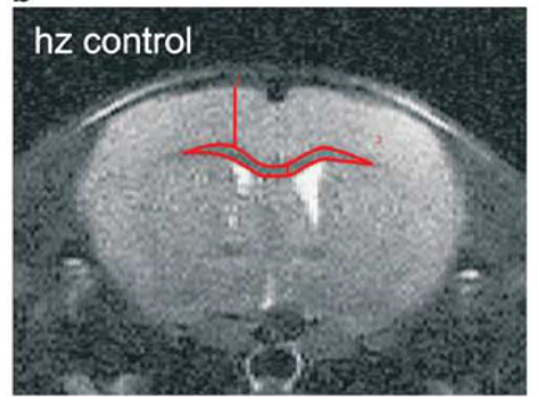

c

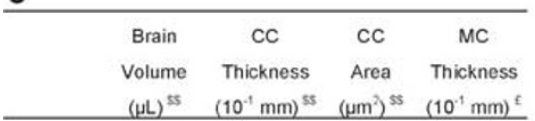

wt control $479.2 \pm 3.2 \quad 4.5 \pm 0.3 \quad 15.8 \pm 1.8 \quad 12.6 \pm 0.3$

wt CNF1 $\quad 470.8 \pm 4.8 \quad 4.7 \pm 0.2 \quad 15.9 \pm 1.2 \quad 13.9 \pm 0.5$

hz control $456.4 \pm 8.3 \quad 3.4 \pm 0.2 \quad 11.0 \pm 0.3 \quad 12.8 \pm 0.4$

hz CNF1 $452.4 \pm 9.1 \quad 3.2 \pm 0.7 \quad 12.7 \pm 2.2 \quad 13.5 \pm 0.5$ d

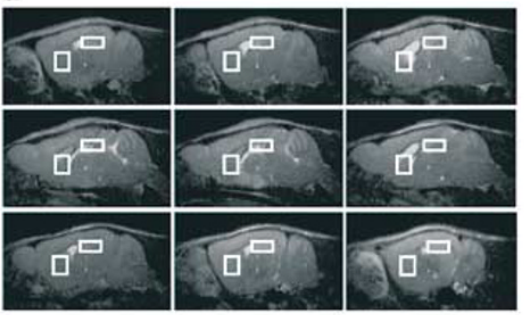

$\square$ 늘 Hippocampus

e

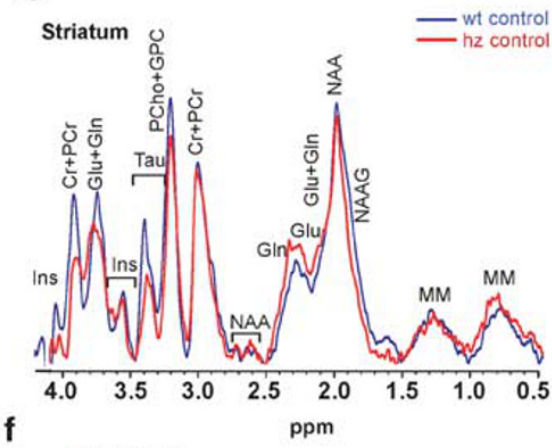

$f$

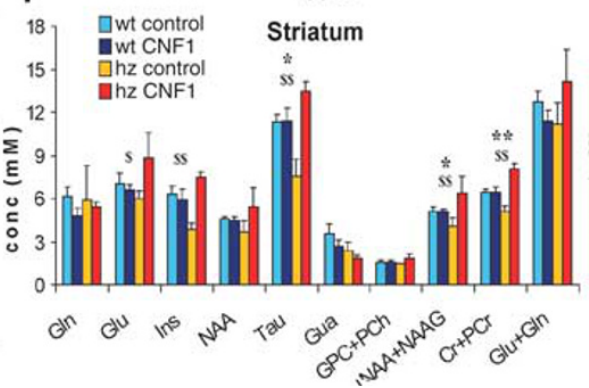

g

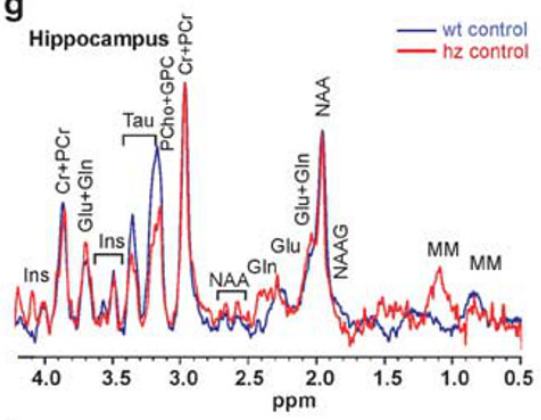

h
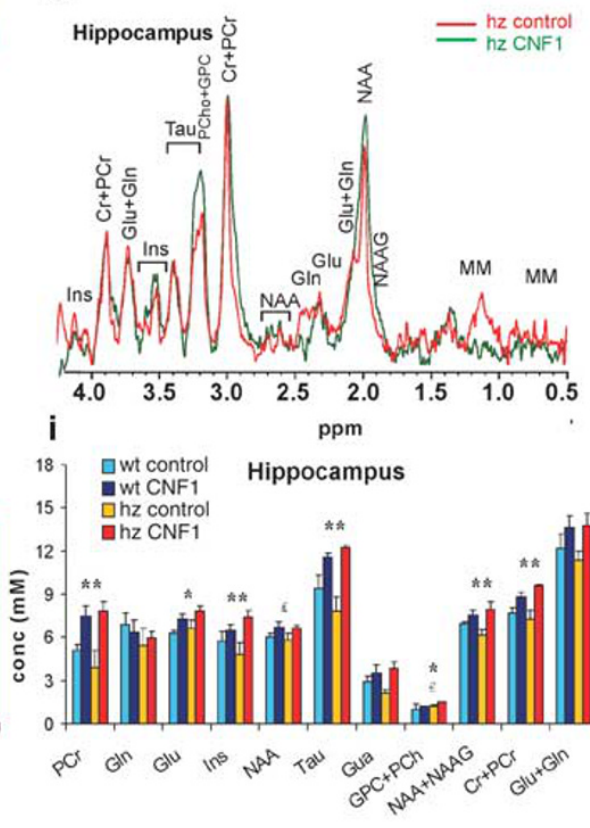

Figure $4 \mathrm{MRI}$ and MRS analyses revealed CNFI-induced brain morphological and metabolic changes. CNFI C866S was used as a control. (a, b) Examples of axial T2-weighted MR images from wt mice and MeCP2-308 hemizygous (hz) littermates, respectively (TR/TEeff $=3200 / 60 \mathrm{~ms}$, ns $=4$, slice thickness $0.6 \mathrm{~mm}, 24$ slices, matrix $256 \times 256$, FOV $=25 \times 25 \mathrm{~mm}^{2}$, which correspond to voxel resolution of $\left.98 \times 98 \times 600 \mu \mathrm{m}^{3}\right)$. (c) Morphometric analyses included total brain volume, motor cortex (MC) thickness and corpus callosum (CC) thickness and area at +1.32 from bregma. Data are means \pm SEM. Effect of genotype: ${ }^{\$} p<0.05,{ }^{\$} p<0.0$ I; Effect of treatment: ${ }^{£} p=0.06$. (d) Examples of in vivo sagittal T2-weighted spin-echo MR images (TR/TEeff $=3000 /$ $60 \mathrm{~ms}$, slice thickness $0.6 \mathrm{~mm}$, ns $=4,17$ slices, FOV $=25 \times 25 \mathrm{~mm}^{2}$, matrix $\left.256 \times 256\right)$. (e, g, h) Examples of in vivo 'H MR spectra (PRESS, TR/TE $=4000 /$ $23 \mathrm{~ms}$, NS = 256) acquired from two voxels (indicated by the white rectangles in d) positioned on hippocampus and striatum. (f, i) Metabolite levels obtained from in vivo ' $\mathrm{H}$ spectra by using a quantitative protocol (which uses water as internal standard) and LCModel fitting program. Metabolite assignments: Cr, creatine; Gln, glutamine; Glu, glutamate; GPC, glicerophosphocholine; Gua, guanidoacetate; Ins, myo-inositol; NAA, nacetylaspartate; NAAG, nacetylaspartylglutamate; PCho, phosphocholine; PCr, phosphocreatine; Tau, taurine. Effect of genotype: $\epsilon_{p}<0.05 ;$ Effect of treatment: ${ }^{\varepsilon_{p}}=0.06$, ${ }^{*} p<0.05,{ }^{*} p<0.0$ I; genotype ${ }^{*}$ treatment interaction: ${ }_{p} p<0.05,{ }^{\$ \$} p<0.01$. Data are mean \pm SEM.

indicates that the beneficial effects on several RTT-related behavioral domains of CNF1 are mediated by a restoration of astrocytic function and involve mitochondria functionality. Our results also provide the first in vivo evidence of astrocytic atrophy in a neurodevelopmental disorder.

Intellectual disability is a core symptom of RTT (Hagberg, 2002). All the RTT mouse models so far available have been reported to show cognitive deficits (for a review, see Ricceri et al, 2008), including MeCP2-308 mice (Moretti et al, 2006). To evaluate CNF1 effects on cognitive performance, two tests were applied (fear-conditioning and novel object recognition), which assess different aspects of cognition and involve different brain areas. No changes were found in the cued version of the fear-conditioning test and in the novel object recognition task. Conversely, CNF1 treatment significantly increased the conditioned response of mutant mice in the contextual (hippocampal-dependent) version of the fear-conditioning test, thus improving their performance. As in mutant mice both anxiety-related profiles and activity levels in a novel environment are not affected by CNF1 administration (Supplementary Results and Supplementary Figure S1), treatment effects on the contextual fearconditioning test are unlikely due to increased fear response per se or habituation to the environment. These results thus support a selective beneficial effect of CNF1 on hippocampal-dependent cognitive processes.

MeCP-308 mice were significantly impaired in nestbuilding abilities, thus confirming a previous report (Moretti et al, 2005). Such a deficit has been suggested to correspond to the apraxia of hand use described in RTT patients (Moretti et al, 2005), a disorder of motor planning, characterized by the loss of the ability to execute or carry 
out purposeful movements (Hagberg, 2002; Leiguarda and Marsden, 2000). Treatment with CNF1 significantly improved the poor performance of mutant mice in nest building, possibly improving the integrated and purposedirected use of mouth and forelimbs.

In line with previous reports (Moretti et al, 2005; Stearns et al, 2007), the evaluation of spontaneous locomotor activity during $24 \mathrm{~h}$ revealed a hypoactive profile during the nocturnal/active phase in mutant mice. Interestingly, no changes were found in locomotion during 1-h open field in mutant mice (Supplementary Results), thus suggesting that motor deficits per se are unlikely to be responsible for the hypoactivity of RTT mice. Administration of CNF1 increased nocturnal levels of spontaneous locomotor activity, thus restoring a wt-like profile in mutant mice. In the open field test, CNF1 also restored wt-like levels of rearings, an exploratory behavior (Supplementary Results and Supplementary Figure S1). As CNF1 did not affect motor coordination in the Dowel test and general locomotor activity in the open field (Supplementary Results), as a whole these results suggest that motivational impairments, rather than motor deficits per se, may be contrasted by CNF1 treatment.

As already reported (Moretti et al, 2006), markers of neuronal dendritic tree and synapses were not affected in this mouse model characterized by a mild RTT phenotype. In line with recent in vitro studies that point to a critical role of astrocytes in the pathophysiology of RTT (Ballas et al, 2009; Maezawa et al, 2009), our immunohistochemical data revealed - for the first time in a RTT mouse model in vivo-a reduction in the number of the two principal types of astrocytes (protoplasmic and fibrous), analyzed in the hippocampus and the corpus callosum, respectively. Clear signs of atrophy were also detected in this cell population in mutants. Indeed, in cultured astrocytes, reducing $\mathrm{MeCP} 2$ levels using RNA interference leads to suppression of glial cell proliferation (Nagai et al, 2005), highlighting the possibility that a similar mechanism may account for the lower number of astrocytes here reported in mutant brains. Although atrophic or degenerative changes in astrocytes have been previously described in chronic neurodegenerative diseases (Rodriguez et al, 2009; Rossi and Volterra, 2009) and major depression (Gosselin et al, 2009; Rajkowska and Miguel-Hidalgo, 2007; Si et al, 2004), this is, to our knowledge, the first report of astrocytic deficits in a neurodevelopmental disorder.

Notably, astrocytic deficits were dramatically reversed five months after CNF1 administration, indicating persistent effects of a single CNF1 icv inoculation. Moreover, treatment effects were evident in both types of astrocytes (protoplasmic astrocytes in hippocampus and fibrous astrocytes in corpus callosum), thus suggesting a widespread effect of CNF1 on this cell population.

Our results are perfectly in line with a report showing that re-expressing Mecp2 in astrocytes of globally Mecp2-null mice improves their behavioral phenotype (Lioy et al, 2011). The results of this recent publication thus suggest that a link between the rescue of astrocytic deficits and the CNF1-induced improvement in RTT symptomatology can be attempted. First, CNF1 treatment significantly improved memory of fear in mutant mice, increasing their conditioned response in the contextual test, a paradigm primarily dependent on hippocampal integrity (Phillips and LeDoux, 1992). Considering the clear role played by astrocytes in hippocampal synaptic plasticity (Barker and Ullian, 2010; Henneberger et al, 2010), the rescue of astrocytic atrophy and the increase in astrocyte number observed in the hippocampus of mutant mice suggests that cognitive improvement induced by CNF1 in symptomatic MeCP2-308 mice may be mediated by its effects on astrocytes. Indeed, the performance of mutant mice was not affected by CNF1 in the cued version of the fearconditioning task and the novel object recognition test (Supplementary Results), which are not hippocampaldependent (Langston et al, 2010; Langston and Wood, 2009). In addition, hippocampal lesioned mice have been reported to build poorer nests (Deacon et al, 2002), thus further supporting a role for improved hippocampal functionality in CNF1-induced behavioral effects.

In MeCP2-308 mouse brains, an abnormal profile of cytokines was also observed (IL-6 was dramatically overexpressed, while TNF- $\alpha$ was downregulated), suggesting that the morphological deficits of astrocytes are accompanied by aberrant functionality. As high levels of IL-6 have also been reported to inhibit pro-inflammatory TNF- $\alpha$ (Petersen and Pedersen, 2005), overexpression of IL-6 is not necessarily in contrast with the observed downregulation of TNF- $\alpha$ and could have a role in RTT etiopathology. Indeed, exposure to high levels of IL-6, as observed during normal aging, in certain neurodegenerative diseases and in mice overexpressing IL-6 in glial cells, results in neuropathological and functional alterations, including decreased synaptic plasticity and impaired neurogenesis (Bellinger et al, 1995; Campbell, 1998; Campbell et al, 1997, 1998; Godbout and Johnson, 2004; Heyser et al, 1997; Vallieres et al, 2002; Vereyken et al, 2007).

In mutant mouse brains, CNF1 significantly counteracted IL-6 increase, but not TNF- $\alpha$ downregulation, suggesting a selective effect of CNF1 on the cytokine network. These results are in line with previous reports showing that the Rho-inhibiting toxin $\mathrm{CdB}$ upregulates inflammatory cytokine expression in astrocytes only in the presence of TLRligand challenges such as LPS (Borysiewicz et al, 2009; Konat et al, 2008), thus suggesting that regulation of Rho GTPase on cytokine expression is dependent on the pathophysiological status of astrocytes. Consistently, we found that Rho GTPases activation did decrease, thus normalizing, IL-6 expression in mutants, without affecting wt levels.

How CNF1 can improve the signs of morphological and functional deficit in astrocytes, however, remains to be defined. CNF1 controls, via RhoGTPases' modulation, the organization of the actin network (Fiorentini et al, 1997), whereas misregulation of actin cytoskeleton is associated with the disruption of GFAP meshwork and drugs preventing actin polymerization alter several physiological astrocytic functions (Lascola et al, 1998; Sergeeva et al, 2000). Moreover, expression of a dominant-negative mutant of the Rac1 GTPase reduces astrocytes process motility and thus functionality (Nishida and Okabe, 2007). Actin remodeling induced by CNF1 might thus have a role in CNF1-induced recovery of astrocytic function.

However, apart from cytoskeleton remodeling, RhoGTPases are known to have several other key roles 
(Heasman and Ridley, 2008). A complex cross-talk among RhoGTPases family members has been found to regulate generation of reactive oxygen species (ROS) (Bokoch and Diebold, 2002; Diebold et al, 2004; Heyworth et al, 1993; Selvakumar et al, 2008), a mechanism that has a pivotal role in host defense and bacterial killing (Koh et al, 2005; Miller and Britigan, 1997). Indeed, MRS analysis revealed that CNF1 increases brain content of Tau, an amino acid that has a role in preventing oxidative damage of mitochondria (Rodriguez-Martinez et al, 2004; Parvez et al, 2008; Schaffer et al, 2009), and increasing overall mitochondrial function (El Idrissi, 2008; El Idrissi and Trenkner, 1999). In RTT patients, oxidative stress markers are increased (De Felice et al, 2009). Consistently with a harmful role of ROS in lipid metabolism and mitochondria functionality, brain profile of choline-containing phospholipids is abnormal in MeCP2 mutant mice (Saywell et al, 2006 and present study) and in patients (Naidu et al, 2001) and structural and functional anomalies of mitochondria and impairments in cerebral energy metabolism have been reported in both RTT patients (Belichenko et al, 2009; Cornford et al, 1994; Dotti et al, 1993; Gibson et al, 2010) and mouse models (Kriaucionis et al, 2006; Saywell et al, 2006).

In full agreement with previous in vitro evidence of CNF1 effects on structure of the mitochondrial network (Miraglia et al, 2007) and in mitochondrial homeostasis (Fiorentini et al, 1998), a CNF1-induced buffering of intracellular energy levels is also confirmed in present study by the increase, in both hippocampal and striatal areas, in $\mathrm{PCr}$ content. MRS also detected an increase in Glu in CNF1treated mice. Although it is not known whether such an increase is of extracellular or intracellular source, it is worth noting that a concomitant elevation in Tau occurred. Notably, the latter is known to counteract Glu-induced excitotoxicity through both the enhancement of mitochondrial function and the regulation of intra-mitochondrial calcium homeostasis (El Idrissi, 2008; El Idrissi and Trenkner, 1999).

As a whole MRS data therefore suggest a role for CNF1 in reducing ROS production and improving mitochondria functionality in RTT brains. Indeed, to resist host defense, several microbes have evolved defense mechanisms against oxidant production, which utilize Rho GTPases (Finlay, 2005; Siemsen et al, 2009). As in vivo studies suggest that CNF1 production by $E$. coli strains mediates bacterial invasion of the host (Rippere-Lampe et al, 2001), it is conceivable that the RhoGTPases-dependent mechanisms that are here proposed to be beneficial in RTT brains (eg, decreasing IL-6 expression and ROS production), may have evolved to modify central host cellular function and allow E. coli to resist host defense (Finlay, 2005; Siemsen et al, 2009).

In conclusion, our study provides the first evidence of the potential efficacy of CNF1 treatment in improving RTT symptomatology and suggests that different Rho-dependent pathways are responsible for the beneficial effects of the proposed treatment. Importantly, the use as control treatment of the mutant protein CNF1 C866S devoid of Rho enzymatic activity unequivocally confirms the pivotal role of RhoGTPases in the rescue of RTT symptoms, although further studies are needed to deeper understand the mechanisms of action of this bacterial toxin. Indeed, although RhoGTPases are critical for several cellular key processes and are involved in many pathological conditions, their pharmacological manipulation is so far still troublesome because of the lack of specific drugs. We believe that CNF1 could therefore represent a totally innovative therapeutic approach for RTT and, possibly, for other neurodevelopmental disorders (Chen et al, 2011a; Hayashi et al, 2007; Ide and Lewis, 2011; Mocholi et al, 2011).

\section{ACKNOWLEDGEMENTS}

We are grateful to Michela Di Nottia for her technical assistance and to Luigia Cancemi for animal care. This research was supported by Jerome Lejeune Foundation (France) to GL, ERARE Project (FP6 European Program) to GL, ISS-NIH 530F/52 to LR and Cure_FXS project under the E-Rare programme to CF and FM.

\section{DISCLOSURE}

The authors declare no conflict of interest.

\section{REFERENCES}

Amir RE, Van den Veyver IB, Wan M, Tran CQ, Francke U, Zoghbi HY (1999). Rett syndrome is caused by mutations in X-linked MECP2, encoding methyl-CpG-binding protein 2. Nat Genet 23: 185-188.

Ballas N, Lioy DT, Grunseich C, Mandel G (2009). Non-cell autonomous influence of MeCP2-deficient glia on neuronal dendritic morphology. Nat Neurosci 12: 311-317.

Barker AJ, Ullian EM (2010). Astrocytes and synaptic plasticity. Neuroscientist 16: 40-50.

Belichenko PV, Wright EE, Belichenko NP, Masliah E, Li HH, Mobley WC et al (2009). Widespread changes in dendritic and axonal morphology in Mecp2-mutant mouse models of Rett syndrome: evidence for disruption of neuronal networks. J Comp Neurol 514: 240-258.

Bellinger FP, Madamba SG, Campbell IL, Siggins GR (1995). Reduced long-term potentiation in the dentate gyrus of transgenic mice with cerebral overexpression of interleukin-6. Neurosci Lett 198: 95-98.

Bokoch GM, Diebold BA (2002). Current molecular models for NADPH oxidase regulation by Rac GTPase. Blood 100: 2692-2696.

Borysiewicz E, Fil D, Konat GW (2009). Rho proteins are negative regulators of TLR2, TLR3, and TLR4 signaling in astrocytes. J Neurosci Res 87: 1565-1572.

Cahoy JD, Emery B, Kaushal A, Foo LC, Zamanian JL, Christopherson KS et al (2008). A transcriptome database for astrocytes, neurons, and oligodendrocytes: a new resource for understanding brain development and function. J Neurosci 28: 264-278.

Campbell IL (1998). Transgenic mice and cytokine actions in the brain: bridging the gap between structural and functional neuropathology. Brain Res Brain Res Rev 26: 327-336.

Campbell IL, Stalder AK, Akwa Y, Pagenstecher A, Asensio VC (1998). Transgenic models to study the actions of cytokines in the central nervous system. Neuroimmunomodulation 5: 126-135.

Campbell IL, Stalder AK, Chiang CS, Bellinger R, Heyser CJ, Steffensen $S$ et al (1997). Transgenic models to assess the pathogenic actions of cytokines in the central nervous system. Mol Psychiatry 2: 125-129.

Canese R, Pisanu ME, Mezzanzanica D, Ricci A, Paris L, Bagnoli M et al (2011). Characterization of in vivo ovarian cancer models 
by quantitative magnetic resonance imaging and spectroscopy. NMR Biomed; E-pub.

Chahrour M, Jung SY, Shaw C, Zhou X, Wong ST, Qin J et al (2008). MeCP2, a key contributor to neurological disease, activates and represses transcription. Science 320: 1224-1229.

Chahrour M, Zoghbi HY (2007). The story of Rett syndrome: from clinic to neurobiology. Neuron 56: 422-437.

Chang Q, Khare G, Dani V, Nelson S, Jaenisch R (2006). The disease progression of Mecp2 mutant mice is affected by the level of BDNF expression. Neuron 49: 341-348.

Chen LY, Rex CS, Babayan AH, Kramar EA, Lynch G, Gall CM et al (2011a). Physiological activation of synaptic Rac $>$ PAK (p-21 activated kinase) signaling is defective in a mouse model of fragile X syndrome. J Neurosci 30: 10977-10984.

Chen Q, Zhu YC, Yu J, Miao S, Zheng J, Xu L et al (2011b). CDKL5, a protein associated with Rett syndrome, regulates neuronal morphogenesis via Rac1 signaling. J Neurosci 30: 12777-12786.

Cornford ME, Philippart M, Jacobs B, Scheibel AB, Vinters HV (1994). Neuropathology of Rett syndrome: case report with neuronal and mitochondrial abnormalities in the brain. J Child Neurol 9: 424-431.

De Felice C, Ciccoli L, Leoncini S, Signorini C, Rossi M, Vannuccini L et al (2009). Systemic oxidative stress in classic Rett syndrome. Free Radic Biol Med 47: 440-448.

De Filippis B, Ricceri L, Laviola G (2010). Early postnatal behavioral changes in the Mecp2-308 truncation mouse model of Rett syndrome. Genes Brain Behav 9: 213-223.

De Viti S, Martino A, Musilli M, Fiorentini C, Diana G (2010). The Rho GTPase activating CNF1 improves associative working memory for object-in-place. Behav Brain Res 212: 78-83.

Deacon RM (2006). Assessing nest building in mice. Nat Protoc 1: 1117-1119.

Deacon RM, Croucher A, Rawlins JN (2002). Hippocampal cytotoxic lesion effects on species-typical behaviours in mice. Behav Brain Res 132: 203-213.

Diana G, Valentini G, Travaglione S, Falzano L, Pieri M, Zona C et al (2007). Enhancement of learning and memory after activation of cerebral Rho GTPases. Proc Natl Acad Sci USA 104: 636-641.

Diebold BA, Fowler B, Lu J, Dinauer MC, Bokoch GM (2004). Antagonistic cross-talk between Rac and Cdc42 GTPases regulates generation of reactive oxygen species. $J$ Biol Chem 279: 28136-28142.

Dotti MT, Manneschi L, Malandrini A, De Stefano N, Caznerale F, Federico A (1993). Mitochondrial dysfunction in Rett syndrome. An ultrastructural and biochemical study. Brain Dev 15: 103-106.

El Idrissi A (2008). Taurine increases mitochondrial buffering of calcium: role in neuroprotection. Amino Acids 34: 321-328.

El Idrissi A, Trenkner E (1999). Growth factors and taurine protect against excitotoxicity by stabilizing calcium homeostasis and energy metabolism. J Neurosci 19: 9459-9468.

Etienne-Manneville S, Hall A (2002). Rho GTPases in cell biology. Nature 420: 629-635.

Falzano L, Fiorentini C, Donelli G, Michel E, Kocks C, Cossart P et al (1993). Induction of phagocytic behaviour in human epithelial cells by Escherichia coli cytotoxic necrotizing factor type 1. Mol Microbiol 9: 1247-1254.

Feltri ML, Suter U, Relvas JB (2008). The function of RhoGTPases in axon ensheathment and myelination. Glia 56: 1508-1517.

Finlay BB (2005). Bacterial virulence strategies that utilize Rho GTPases. Curr Top Microbiol Immunol 291: 1-10.

Fiorentini C, Fabbri A, Flatau G, Donelli G, Matarrese P, Lemichez $\mathrm{E}$ et al (1997). Escherichia coli cytotoxic necrotizing factor 1 (CNF1), a toxin that activates the Rho GTPase. J Biol Chem 272: 19532-19537.

Fiorentini C, Matarrese P, Straface E, Falzano L, Fabbri A, Donelli $\mathrm{G}$ et al (1998). Toxin-induced activation of Rho GTP-binding protein increases Bcl-2 expression and influences mitochondrial homeostasis. Exp Cell Res 242: 341-350.

Gibson JH, Slobedman B, K NH, Williamson SL, Minchenko D, ElOsta A et al (2010). Downstream targets of methyl CpG binding protein 2 and their abnormal expression in the frontal cortex of the human Rett syndrome brain. BMC Neurosci 11: 53 .

Godbout JP, Johnson RW (2004). Interleukin-6 in the aging brain. I Neuroimmunol 147: 141-144.

Gonzales ML, LaSalle JM (2010). The role of MeCP2 in brain development and neurodevelopmental disorders. Curr Psychiatry Rep 12: 127-134.

Gosselin RD, Gibney S, O’Malley D, Dinan TG, Cryan JF (2009). Region specific decrease in glial fibrillary acidic protein immunoreactivity in the brain of a rat model of depression. Neuroscience 159: 915-925.

Gotoh H, Suzuki I, Maruki K, Mitomo M, Hirasawa K, Sasaki N (2001). Magnetic resonance imaging and clinical findings examined in adulthood-studies on three adults with Rett syndrome. Brain Dev 23(Suppl 1): S118-S121.

Hagberg B (2002). Clinical manifestations and stages of Rett syndrome. Ment Retard Dev Disabil Res Rev 8: 61-65.

Hall A (2005). Rho GTPases and the control of cell behaviour. Biochem Soc Trans 33: 891-895.

Hayashi ML, Rao BS, Seo JS, Choi HS, Dolan BM, Choi SY et al (2007). Inhibition of p21-activated kinase rescues symptoms of fragile X syndrome in mice. Proc Natl Acad Sci USA 104: 11489-11494.

Heasman SJ, Ridley AJ (2008). Mammalian Rho GTPases: new insights into their functions from in vivo studies. Nat Rev Mol Cell Biol 9: 690-701.

Henneberger C, Papouin T, Oliet SH, Rusakov DA (2010). Longterm potentiation depends on release of $\mathrm{D}$-serine from astrocytes. Nature 463: 232-236.

Heyser CJ, Masliah E, Samimi A, Campbell IL, Gold LH (1997). Progressive decline in avoidance learning paralleled by inflammatory neurodegeneration in transgenic mice expressing interleukin 6 in the brain. Proc Natl Acad Sci USA 94: 1500-1505.

Heyworth PG, Knaus UG, Xu X, Uhlinger DJ, Conroy L, Bokoch GM et al (1993). Requirement for posttranslational processing of Rac GTP-binding proteins for activation of human neutrophil NADPH oxidase. Mol Biol Cell 4: 261-269.

Hite KC, Adams VH, Hansen JC (2009). Recent advances in MeCP2 structure and function. Biochem Cell Biol 87: 219-227.

Ide M, Lewis DA (2011). Altered cortical CDC42 signaling pathways in schizophrenia: implications for dendritic spine deficits. Biol Psychiatry 68: 25-32.

Koh AL, Sun CX, Zhu F, Glogauer M (2005). The role of Racl and Rac2 in bacterial killing. Cell Immunol 235: 92-97.

Konat GW, Krasowska-Zoladek A, Kraszpulski M (2008). Statins enhance toll-like receptor 4-mediated cytokine gene expression in astrocytes: implication of Rho proteins in negative feedback regulation. J Neurosci Res 86: 603-609.

Kriaucionis S, Paterson A, Curtis J, Guy J, Macleod N, Bird A (2006). Gene expression analysis exposes mitochondrial abnormalities in a mouse model of Rett syndrome. Mol Cell Biol 26: 5033-5042.

Langston RF, Stevenson CH, Wilson CL, Saunders I, Wood ER (2010). The role of hippocampal subregions in memory for stimulus associations. Behav Brain Res 215: 275-291.

Langston RF, Wood ER (2009). Associative recognition and the hippocampus: differential effects of hippocampal lesions on object-place, object-context and object-place-context memory. Hippocampus 20: 1139-1153.

Lascola CD, Nelson DJ, Kraig RP (1998). Cytoskeletal actin gates a Cl- channel in neocortical astrocytes. J Neurosci 18: 1679-1692.

Leiguarda RC, Marsden CD (2000). Limb apraxias: higherorder disorders of sensorimotor integration. Brain 123(Part 5): $860-879$ 
Lemichez E, Flatau G, Bruzzone M, Boquet $\mathrm{P}$, Gauthier M (1997). Molecular localization of the Escherichia coli cytotoxic necrotizing factor CNF1 cell-binding and catalytic domains. Mol Microbiol 24: 1061-1070.

Lioy DT, Garg SK, Monaghan CE, Raber J, Foust KD, Kaspar BK et al (2011). A role for glia in the progression of Rett's syndrome. Nature 475: 497-500.

Luo L (2000). Rho GTPases in neuronal morphogenesis. Nat Rev Neurosci 1: 173-180.

Maezawa I, Swanberg S, Harvey D, LaSalle JM, Jin LW (2009). Rett syndrome astrocytes are abnormal and spread MeCP2 deficiency through gap junctions. J Neurosci 29: 5051-5061.

Mahmood A, Bibat G, Zhan AL, Izbudak I, Farage L, Horska A et al (2010). White matter impairment in Rett syndrome: diffusion tensor imaging study with clinical correlations. AJNR Am J Neuroradiol 31: 295-299.

McAfoose J, Baune BT (2009). Evidence for a cytokine model of cognitive function. Neurosci Biobehav Rev 33: 355-366.

McGill BE, Bundle SF, Yaylaoglu MB, Carson JP, Thaller C, Zoghbi HY (2006). Enhanced anxiety and stress-induced corticosterone release are associated with increased Crh expression in a mouse model of Rett syndrome. Proc Natl Acad Sci USA 103: 18267-18272.

Miller RA, Britigan BE (1997). Role of oxidants in microbial pathophysiology. Clin Microbiol Rev 10: 1-18.

Miraglia AG, Travaglione S, Meschini S, Falzano L, Matarrese P, Quaranta MG et al (2007). Cytotoxic necrotizing factor 1 prevents apoptosis via the Akt/IkappaB kinase pathway: role of nuclear factor-kappaB and Bcl-2. Mol Biol Cell 18: 2735-2744.

Miyamoto Y, Yamauchi J, Tanoue A, Wu C, Mobley WC (2006). TrkB binds and tyrosine-phosphorylates Tiam1, leading to activation of Racl and induction of changes in cellular morphology. Proc Natl Acad Sci USA 103: 10444-10449.

Mocholi E, Ballester-Lurbe B, Arque G, Poch E, Peris B, Guerri C et al (2011). RhoE deficiency produces postnatal lethality, profound motor deficits and neurodevelopmental delay in mice. PLoS One 6: e19236.

Moretti P, Bouwknecht JA, Teague R, Paylor R, Zoghbi HY (2005). Abnormalities of social interactions and home-cage behavior in a mouse model of Rett syndrome. Hum Mol Genet 14: 205-220.

Moretti P, Levenson JM, Battaglia F, Atkinson R, Antalffy B, Amstrong D et al (2006). Learning and memory and synaptic plasticity are impaired in a mouse model of Rett syndrome. J Neurosci 26: 319-327.

Nag N, Moriuchi JM, Peitzman CG, Ward BC, Kolodny NH, Berger-Sweeney JE (2009). Environmental enrichment alters locomotor behaviour and ventricular volume in Mecp2 1lox mice. Behav Brain Res 196: 44-48.

Nagai K, Miyake K, Kubota T (2005). A transcriptional repressor $\mathrm{MeCP} 2$ causing Rett syndrome is expressed in embryonic nonneuronal cells and controls their growth. Brain Res Dev Brain Res 157: 103-106.

Naidu S, Kaufmann WE, Abrams MT, Pearlson GD, Lanham DC, Fredericksen KA et al (2001). Neuroimaging studies in Rett syndrome. Brain Dev 23(Suppl 1): S62-S71.

Nakayama AY, Harms MB, Luo L (2000). Small GTPases Rac and Rho in the maintenance of dendritic spines and branches in hippocampal pyramidal neurons. J Neurosci 20: 5329-5338.

Nishida H, Okabe S (2007). Direct astrocytic contacts regulate local maturation of dendritic spines. J Neurosci 27: 331-340.

Ogier M, Katz DM (2008). Breathing dysfunction in Rett syndrome: understanding epigenetic regulation of the respiratory network. Respir Physiol Neurobiol 164: 55-63.

Parvez S, Tabassum H, Banerjee BD, Raisuddin S (2008). Taurine prevents tamoxifen-induced mitochondrial oxidative damage in mice. Basic Clin Pharmacol Toxicol 102: 382-387.

Pavone F, Luvisetto S, Marinelli S, Straface E, Fabbri A, Falzano L et al (2009). The Rac GTPase-activating bacterial protein toxin
CNF1 induces analgesia up-regulating mu-opioid receptors. Pain 145: 219-229.

Petersen AM, Pedersen BK (2005). The anti-inflammatory effect of exercise. J Appl Physiol 98: 1154-1162.

Phillips RG, LeDoux JE (1992). Differential contribution of amygdala and hippocampus to cued and contextual fear conditioning. Behav Neurosci 106: 274-285.

Popoli P, Pintor A, Domenici MR, Frank C, Tebano MT, Pezzola A et al (2002). Blockade of striatal adenosine A2A receptor reduces, through a presynaptic mechanism, quinolinic acidinduced excitotoxicity: possible relevance to neuroprotective interventions in neurodegenerative diseases of the striatum. J Neurosci 22: 1967-1975.

Provencher SW (1993). Estimation of metabolite concentrations from localized in vivo proton NMR spectra. Magn Reson Med 30: 672-679.

Rajkowska G, Miguel-Hidalgo JJ (2007). Gliogenesis and glial pathology in depression. CNS Neurol Disord Drug Targets 6: 219-233.

Ramakers GJ (2002). Rho proteins, mental retardation and the cellular basis of cognition. Trends Neurosci 25: 191-199.

Ricceri L, De Filippis B, Fuso A, Laviola G (2011). Cholinergic hypofunction in MeCP2-308 mice: beneficial neurobehavioural effects of neonatal choline supplementation. Behav Brain Res 221: 623-629.

Ricceri L, De Filippis B, Laviola G (2008). Mouse models of Rett syndrome: from behavioural phenotyping to preclinical evaluation of new therapeutic approaches. Behav Pharmacol 19: 501-517.

Rippere-Lampe KE, O’Brien AD, Conran R, Lockman HA (2001). Mutation of the gene encoding cytotoxic necrotizing factor type $1(\operatorname{cnf}(1))$ attenuates the virulence of uropathogenic Escherichia coli. Infect Immun 69: 3954-3964.

Rodriguez-Martinez E, Rugerio-Vargas C, Rodriguez AI, BorgonioPerez G, Rivas-Arancibia S (2004). Antioxidant effects of taurine, vitamin $\mathrm{C}$, and vitamin $\mathrm{E}$ on oxidative damage in hippocampus caused by the administration of 3-nitropropionic acid in rats. Int J Neurosci 114: 1133-1145.

Rodriguez JJ, Olabarria M, Chvatal A, Verkhratsky A (2009). Astroglia in dementia and Alzheimer's disease. Cell Death Differ 16: 378-385.

Rossi D, Volterra A (2009). Astrocytic dysfunction: insights on the role in neurodegeneration. Brain Res Bull 80: 224-232.

Saywell V, Viola A, Confort-Gouny S, Le Fur Y, Villard L, Cozzone PJ (2006). Brain magnetic resonance study of Mecp2 deletion effects on anatomy and metabolism. Biochem Biophys Res Commun 340: 776-783.

Schaffer SW, Azuma J, Mozaffari M (2009). Role of antioxidant activity of taurine in diabetes. Can J Physiol Pharmacol 87: 91-99.

Schmidt G, Sehr P, Wilm M, Selzer J, Mann M, Aktories K (1997). Gln 63 of Rho is deamidated by Escherichia coli cytotoxic necrotizing factor-1. Nature 387: 725-729.

Schmidt G, Selzer J, Lerm M, Aktories K (1998). The Rhodeamidating cytotoxic necrotizing factor 1 from Escherichia coli possesses transglutaminase activity. Cysteine 866 and histidine 881 are essential for enzyme activity. J Biol Chem 273: $13669-13674$.

Selvakumar B, Hess DT, Goldschmidt-Clermont PJ, Stamler JS (2008). Co-regulation of constitutive nitric oxide synthases and NADPH oxidase by the small GTPase Rac. FEBS Lett 582: 2195-2202.

Sergeeva M, Ubl JJ, Reiser G (2000). Disruption of actin cytoskeleton in cultured rat astrocytes suppresses ATP- and bradykinin-induced $[\mathrm{Ca}(2+)](\mathrm{i})$ oscillations by reducing the coupling efficiency between $\mathrm{Ca}(2+)$ release, capacitative $\mathrm{Ca}(2+)$ entry, and store refilling. Neuroscience 97: 765-769.

Shahbazian M, Young J, Yuva-Paylor L, Spencer C, Antalffy B, Noebels J et al (2002). Mice with truncated 
MeCP2 recapitulate many Rett syndrome features and display hyperacetylation of histone H3. Neuron 35: 243-254

Si X, Miguel-Hidalgo JJ, O’Dwyer G, Stockmeier CA, Rajkowska G (2004). Age-dependent reductions in the level of glial fibrillary acidic protein in the prefrontal cortex in major depression. Neuropsychopharmacology 29: 2088-2096.

Siemsen DW, Kirpotina LN, Jutila MA, Quinn MT (2009). Inhibition of the human neutrophil NADPH oxidase by Coxiella burnetii. Microbes Infect 11: 671-679.

Stearns NA, Schaevitz LR, Bowling H, Nag N, Berger UV, BergerSweeney J (2007). Behavioral and anatomical abnormalities in Mecp2 mutant mice: a model for Rett syndrome. Neuroscience 146: 907-921.

Swinny JD, Valentino RJ (2006). Corticotropin-releasing factor promotes growth of brain norepinephrine neuronal processes through Rho GTPase regulators of the actin cytoskeleton in rat. Eur J Neurosci 24: 2481-2490.

Tashiro A, Minden A, Yuste R (2000). Regulation of dendritic spine morphology by the rho family of small GTPases: antagonistic roles of Rac and Rho. Cereb Cortex 10: 927-938.

Vallieres L, Campbell IL, Gage FH, Sawchenko PE (2002). Reduced hippocampal neurogenesis in adult transgenic mice with chronic astrocytic production of interleukin-6. J Neurosci 22: 486-492.

van Galen EJ, Ramakers GJ (2005). Rho proteins, mental retardation and the neurobiological basis of intelligence. Prog Brain Res 147: 295-317.

Vereyken EJ, Bajova H, Chow S, de Graan PN, Gruol DL (2007). Chronic interleukin-6 alters the level of synaptic proteins in hippocampus in culture and in vivo. Eur J Neurosci 25: 3605-3616.

Wilcox RG (ed) (1987). New Statistical Procedures for the Social Sciences. Lawrence Erlbaum Associates, NJ, pp. 187-189.

Supplementary Information accompanies the paper on the Neuropsychopharmacology website (http://www.nature.com/npp) 